\title{
Characterization and Long-term Performances of the Radon Trapping Facility Operating at the Modane Underground Laboratory
}

\author{
R. Hodák ${ }^{1}$, F. Perrot ${ }^{2}$, V. Brudanin ${ }^{3}$, J. Busto ${ }^{4}$, M. Havelcová ${ }^{5}$, \\ J. Hůlka ${ }^{6}$, S. Jullian ${ }^{7}$, O. Kochetov ${ }^{3}$, D. Lalanne ${ }^{7}$, P. Loaiza ${ }^{7,8}$,

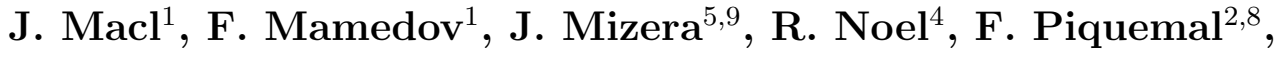 \\ E. Rukhadze ${ }^{1}$, P. Rulík ${ }^{6}$, K. Smolek ${ }^{1}$, B. Soulé ${ }^{2}$, T. Suchá ${ }^{6}$, I. \\ Svetlík $^{9}$, I. Štekl ${ }^{1}$, G. Warot ${ }^{8}$, M. Zampaolo ${ }^{8}$, M. Žaloudková ${ }^{5}$ \\ ${ }^{1}$ Institute of Experimental and Applied Physics, Czech Technical University in \\ Prague, CZ-11000 Prague, Czech Republic \\ ${ }^{2}$ CENBG, Université de Bordeaux, CNRS/IN2P3, F-33175 Gradignan, France \\ 3 Joint Institute for Nuclear Research, Dubna, RU-141980, Russian Federation \\ ${ }^{4}$ Aix Marseille Université,CNRS/IN2P3, CPPM UMR 7346, F-13288 Marseille, \\ France \\ ${ }^{5}$ Institute of Rock Structure and Mechanics of the Czech Academy of Sciences, \\ CZ-18209 Prague, Czech Republic \\ ${ }^{6}$ National Radiation Protection Institute, CZ-14000 Prague, Czech Republic \\ 7 Univ Paris Saclay, CNRS, IN2P3, Univ Paris 11, LAL, F-91405 Orsay, France \\ 8 Laboratoire Souterrain de Modane, F-73500 Modane, France \\ ${ }^{9}$ Nuclear Physics Institute of the Czech Academy of Sciences, CZ-25068 Řež, Czech \\ Republic \\ E-mail: rastislav.hodak@utef.cvut.cz, frederic.perrot@u-bordeaux.fr \\ April 2019
}

\begin{abstract}
Radon is one of the main potential source of background for any rare event experiments like neutrinoless double beta decay or dark matter experiments. The Radon Trapping Facility (RTF) installed in 2004 at the Modane Underground Laboratory (LSM) has been running for almost 9 years providing a radon-purified air at the level of $10 \mathrm{mBq} / \mathrm{m}^{3}$ compared to $20 \mathrm{~Bq} / \mathrm{m}^{3}$ in the laboratory. The radon suppression principle is based on radon physical adsorption using pumping cooled compressed air at $-55{ }^{\circ} \mathrm{C}$ through a column filled with $\mathrm{K} 48$ activated charcoal. After disassembling of the RTF, the $2.6 \mathrm{~m}$ height charcoal column has been divided in several layers in order to study with different techniques the dynamic adsorption coefficient ( $K$ factor) as a function of the depth and the radon spatial trapping profile by measuring the ${ }^{210} \mathrm{~Pb}$ activity. It has been demonstrated that after a decade of running, most of the radon adsorption capacity of the RTF remains constant excepted for the first $20 \mathrm{~cm}$. A radon mean free path of about $30 \mathrm{~cm}$ has been derived in a coherent manner from two independent analysis leading to a radon suppression factor of the RTF ranging from 1830 to 6 790. These results are consistent with the suppression factor of 2000 measured during the operation of the RTF, proving its capacity to purify the radon in the LSM air by more than 3 orders of magnitude during 9 years. In addition to ${ }^{210} \mathrm{~Pb}$
\end{abstract}


activity exhibiting an exponential decay with the depth of activated charcoal, other radioisotopes $\left({ }^{226} \mathrm{Ra},{ }^{40} \mathrm{~K}\right.$ and $\left.{ }^{137} \mathrm{Cs}\right)$ have been measured by low background gamma spectrometry and will be also discussed in this paper.

Keywords: radon, charcoal, spectroscopy, $\beta \beta$-decay

Submitted to: J. Phys. G: Nucl. Part. Phys.

\section{Introduction}

The investigation of very rare processes in particle or nuclear physics such as neutrinoless double beta decay $(0 \nu \beta \beta)$ or direct dark matter detection requires very low radioactive background conditions. The backgrounds may have different origin: cosmic radiations, radioactivity of the environment, radioactive impurities in the detector, constructive materials and shielding. One of the ultimate background is the radon, a noble gas naturally present in the air and formed in the ${ }^{238} \mathrm{U}$ radioactive decay chain through the radium $\left({ }^{226} \mathrm{Ra}\right)$ parent nucleus. To reduce this source of background, a solution is to purify the air or the carrier gas by removing the radon atoms. To do so, a dedicated facility has been built at the Modane Underground Laboratory (French: Laboratoire Souterrain de Modane - LSM) primarily for the NEMO-3 experiment looking for $0 \nu \beta \beta$ process [1] but also used nowadays for other ultra-low background experiments running in the laboratory.

The activity of radon in the air of the LSM is at the level of $20 \mathrm{~Bq} / \mathrm{m}^{3}$. The LSM air is renewed two times per hour with fresh air from outside the mountain delivered through the tunnel ventilation system. The radon rate is extremely variable, depending on the day/week period, and is correlated to various parameters like outside weather and conditions of the tunnel ventilation. In 2004, it has been observed that this rate had a huge impact on the level of radon background inside the NEMO-3 detector. In order to reduce the radon level in the detector volume, an airtight tent was built around in which radon-free air was delivered by the Radon Trapping Facility (RTF). This method allowed to reduce the concentration of radon in the incoming air and thus inside the NEMO-3 gas [2, 3, 4].

The air purification system has been initially developed by the Super-Kamiokande collaboration [5] as well as the high sensitive radon detectors able to measure radon activity down to few $\mathrm{mBq} / \mathrm{m}^{3}[6]$. A RTF based on the Super-Kamiokande system and using activated charcoal has been installed in 2004 at LSM. The online radon monitoring performed at the exit of the RTF using a high sensitive electrostatic radon detector has demonstrated a reduction by 3 orders of magnitude of the radon level in the air, from about $20 \mathrm{~Bq} / \mathrm{m}^{3}$ down to $10 \mathrm{mBq} / \mathrm{m}^{3}$ [9]. After more than 9 years of running, the RTF was stopped and disassembled in 2014 for maintenance operations. It was thus a unique opportunity to analyze the K48 activated charcoal filled in the RTF by several techniques. The $3 \mathrm{~m}$ height charcoal column has been divided in several layers in order 
to study both the dynamic adsorption coefficient ( $K$-factor) along the column with a possible ageing effect and also the radon spatial trapping profile by measuring the long half-life isotope ${ }^{210} \mathrm{~Pb}$ (22.3 years) by low background gamma spectrometry.

In section 2, we will remind the main ingredients of the radon adsorption processes which motivate the design of the RTF and the use of several techniques to analyse the activated charcoal. Details on the RTF itself will be given in section 3. Section 4 will describe the protocol adopted to divide the charcoal column in several layers and to prepare the samples using different containers. The description of the setups for $K$ factor and gamma spectrometry measurements and the associated results will be given in section 5 and 6 , respectively. The results will be discussed in section 7 . Additional chemical analyses are also briefly described in section 8 before conclusion.

\section{Radon adsorption process and modelization}

Radon is a noble gas, chemically inert. Thus the only way to trap it is by physical adsorption called physisorption on a given material through the van der Waals forces. Radon atoms are not definitely trapped but slowed in their path due to adsorption/desorption processes. The goal is to slow down the radon atoms in such a way that they will decay before exiting the material. The radon daughters are not chemically inert so they are definitely trapped in the adsorbent material. When flushing radon with a carrier gas through a given material, the trapping lifetime of the radon is depending on several parameters: the temperature, the porosity of the solid material, the size of the pores, the partial pressure and the competition with the carrier gas.

The size of the pore must be at least of the order of the size of the radon atom. However, the bigger is the size of the pore, the shorter will be the trapping lifetime. The temperature has also a huge impact on the trapping lifetime. The lower is the temperature, the longer will be the trapping lifetime so it is usual to work at temperature well below room temperature. The radon adsorption in a given material is also depending on the concentration of the pores or the high degree of microporosity. For active charcoal adsorbent, it is common to have a surface area in excess greater than $1000 \mathrm{~m}^{2}$ per gram. The size of the carrier atom and thus the nature of the carrier gas is also important because it can be in competition with the radon adsorption by the pores.

The radon adsorption can be estimated from the ratio of radon concentration in an adsorbent to the radon concentration in the carrier gas going to the adsorbent. This ratio, called dynamic adsorption coefficient $K$ (or $K$-factor) and expressed in $\mathrm{m}^{3} / \mathrm{kg}$, is evaluated when the equilibrium between adsorption and desorption in the sample is reached, as shown in Equation 1:

$$
K=\frac{C_{a}}{C_{g}}
$$


where $C_{a}$ is the radon concentration in the adsorbent (in $\mathrm{Bq} / \mathrm{kg}$ ) and $C_{g}$ is the radon concentration in the gas (in $\mathrm{Bq} / \mathrm{m}^{3}$ ).

In chromatography, an important parameter is the average retention time $\tau_{R}$. It represents the time needed by an atom to cross the trapping column when the gas is flushed at a certain flow [7]. The mean retention time in the adsorbent material is then the result of a competition between the trapping time of the atom in a pore and the transportation time between two trapping processes. It is known that this parameter is related to the gas flow $\Phi$ in $\mathrm{m}^{3} / \mathrm{h}$, the mass of adsorbent $M$ in $\mathrm{kg}$ and the dynamic adsorption coefficient $K$ in $\mathrm{m}^{3} / \mathrm{kg}$ by the following Equation 2:

$$
\tau_{R}=\frac{K M}{\Phi}
$$

In a chromatographic column with a length $L$, one can also define the mean velocity $v$ of a radon atom in the adsorbent material by $v=L / \tau_{R}$. The radon atoms are radioactive with a mean lifetime $\tau$ of 5.5 days (or a half-life $\mathrm{T}_{1 / 2}=3.8$ days). In this case, if the mean retention time of a chromatographic column is much shorter than the radon lifetime, then most of the radon atoms will exit the material. On the contrary, if it is of the order of magnitude or greater than the radon lifetime, most of the radon atoms will decay in the material. It depends thus both on the mean velocity and the size of the column.

The time for a radon atom to reach a given distance $x$ in the sorbent material during a time interval $t$ is then defined by $t=x / v$. Considering the radioactive decay law, one can translate the time relation in a spatial relation in the following Equation 3:

$$
N(x)=N_{0} e^{-\frac{x}{X}}
$$

where $N(x)$ and $N_{0}$ are the number of radon atoms present at a depth $x$ and $x=0$, respectively, and $X=\frac{\Phi \tau}{K M}$ is the mean free path of a radon atom before decaying.

After decaying, the daughter nucleus ${ }^{218} \mathrm{Po}$ is no more a noble gas and is stopped where the radon has decayed. Thus, one expects a spatial exponential profile of the radon daughter nuclei in the material sorbent along the $x$ direction of the gas flow. To study a posteriori the radon trapping spatial profile, it is suitable to measure its daughter nuclei, especially the long half-life ${ }^{210} \mathrm{~Pb}$ nucleus $\left(\mathrm{T}_{1 / 2}=22.3\right.$ years $)$. This nucleus is a waiting-point which accumulates all the radon atoms that have decayed at a given location in the material sorbent. So the ${ }^{210} \mathrm{~Pb}$ activity will be directly correlated to the ${ }^{222} \mathrm{Rn}$ accumulation and is supposed to follow the same kind of equation as Equation 3.

$$
A_{P b}(x)=A_{P b}(0) e^{-\frac{x}{X}},
$$

where $A_{P b}(x)$ and $A_{P b}(0)$ are the ${ }^{210} \mathrm{~Pb}$ activity at a thickness $x$ and $x=0$ respectively and $X$ the radon mean free path already defined in Equation 3. The ${ }^{210} \mathrm{~Pb}$ activity is an indirect access to the radon trapping spatial profile and will be measured by gamma spectrometry using the $46.5 \mathrm{keV}$ gamma line.

This is why we propose in this article to study the sampling layer by layer of the 


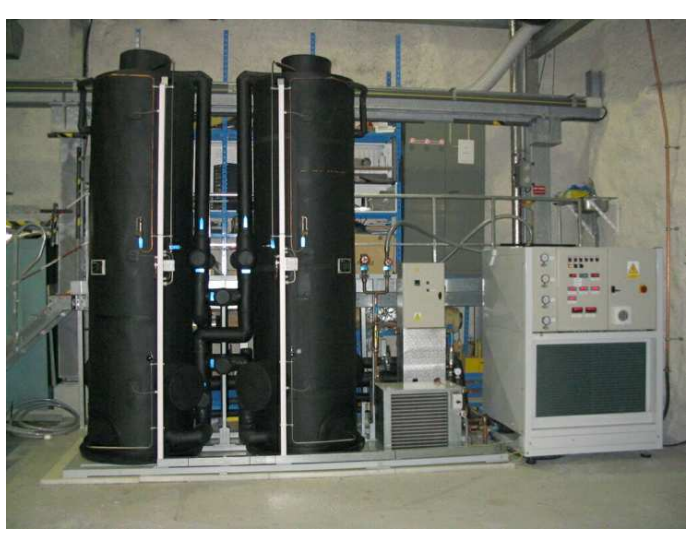

(a)

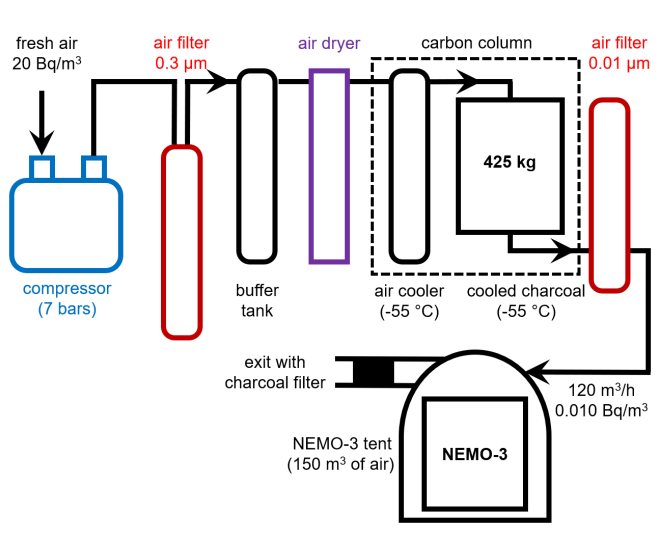

(b)

Figure 1. (a) The photo of the RTF with two columns shown but only one used. (b) The principle of the RTF.

charcoal column installed at LSM by $K$-factor measurements (section 5 ) and by lowbackground gamma spectrometry measurements (section 6).

\section{Description of the Radon Trapping Facility}

Based on the Super-Kamiokande proposal the RTF was designed by the Czech team of the NEMO-3 collaboration and built by the Czech company ATEKO. Before the installation of the RTF at LSM in September 2004 it had been tested at the IEAP CTU in Prague. In this facility trapping of radon from cooled compressed air is based on a physical adsorption method applied on an activated charcoal. The air is cooled at $-55^{\circ} \mathrm{C}$ before entering in the charcoal column. Advantage of this common used method is a huge effective surface area of the porous charcoal. The specifications of the RTF are following: the compressor ( 7 bars $)$, the filtration with the oil separator $(0.03 \mu \mathrm{m})$ and the dust separator $(0.1 \mu \mathrm{m})$, the air dryer with a dew point at $-70{ }^{\circ} \mathrm{C}$ for 8.5 bars, the cooling unit and an adsorption column with an internal diameter of $0.6 \mathrm{~m}$ and $3 \mathrm{~m}$ high, loaded with $425 \mathrm{~kg}$ of charcoal (activated charcoal K48 made of coconut shells from Silcarbon Aktivkohle [8]). The photo and the principle of the RTF are shown in the Figure 1. The radon-free air is flushed around all the experiments installed in LSM, i.e. NEMO-3 (dismantled in 2012) and EDELWEISS experiments and the HPGe platform with a typical flow of $120 \mathrm{~m}^{3} / \mathrm{h}$. The input and output air have a temperature of approximately 25 and $20{ }^{\circ} \mathrm{C}$, respectively. The input air have typical radon activity of $20 \mathrm{~Bq} / \mathrm{m}^{3}$ and the air at the exit of the RTF has been measured with high sensitivity electrostatic radon detectors at the average level of $10 \mathrm{mBq} / \mathrm{m}^{3}$ [9], leading to a radon suppression factor of about 2000 . 


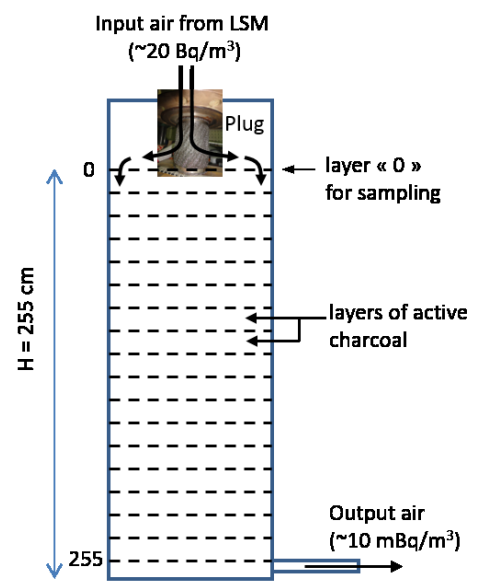

(a)

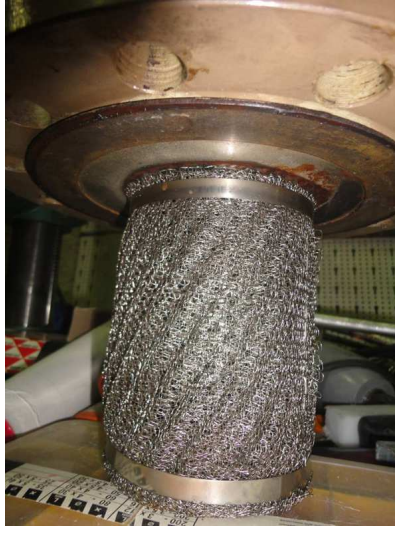

(b)

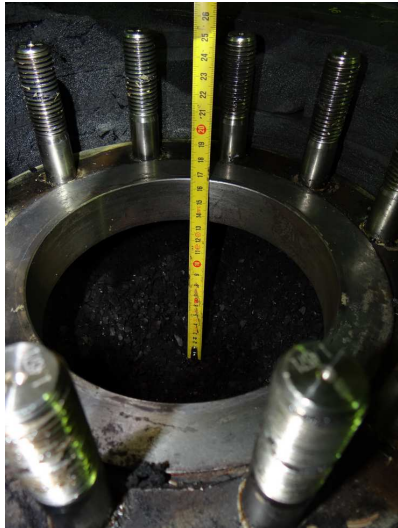

(c)

Figure 2. (a) Schematic view of the sampling from the charcoal column. (b) Plug of the charcoal column from which the input air was flushed. (c) Top view of the charcoal column after removing the plug.

Table 1. Overview of different containers with the charcoal samples.

\begin{tabular}{cccccc}
\hline Container type & Volume $\left[\mathrm{cm}^{3}\right]$ & Number of samples & Depth range $[\mathrm{cm}]$ & Mass per sample $[\mathrm{g}]$ & Uncertainty $[\mathrm{g}]$ \\
\hline Marinelli beaker & 4000 & 15 & $0-260$ & $1400-1730$ & 1 \\
Marinelli beaker & 600 & 13 & $0-145$ & $300-500$ & 1 \\
Petri box & 75 & 27 & $0-260$ & $25.0-35.0$ & 0.1 \\
Plastic tubes & 5.8 & 26 & $0-260$ & $1.70-2.20$ & 0.01 \\
$K$-factor container & few $\mathrm{cm}^{3}$ & 9 & $0-260$ & few grams & - \\
\hline
\end{tabular}

\section{Charcoal sampling}

Beginning of January 2014 the RTF was opened (see Figure 2). Sampling of charcoal was realized from the inlet of the charcoal column at the top with help of a vacuum cleaner. The first $5 \mathrm{~cm}$ of the column were free of sorbent. Then the first layer with a non-homogeneous thickness between $5 \mathrm{~cm}$ and $13 \mathrm{~cm}$ depth located on the sides of the column was sucked out in order to start the sampling at a well-defined depth along the radius. This non-homogeneous thickness was due to the plug which has removed a part of the charcoal at the center of the column. Thus, the $13 \mathrm{~cm}$ depth has been defined as the "zero" mean layer depth (MLD) position in the following analysis. The sampling has been performed layer by layer of about 5 or $10 \mathrm{~cm}$ thickness from 0 to $255 \mathrm{~cm}$ as it is illustrated in Figure 2. A layer is defined by its MLD taken at the center of the layer. The uncertainty of the MLD has been evaluated to be $1.5 \mathrm{~cm}$.

Several containers have been used for charcoal sampling. Due to self-absorption, large volume containers have been used in order to measure the high energy gamma lines from radionuclides ${ }^{40} \mathrm{~K}$ and ${ }^{137} \mathrm{Cs}$ with a good efficiency and to have a more representative mass sample. Smaller containers have been also used in order to measure the low energy gammas from ${ }^{210} \mathrm{~Pb}$ and ${ }^{226} \mathrm{Ra}$ (see section 6). Typical information about the type of containers and the mass of each sample are presented in Table 1. 


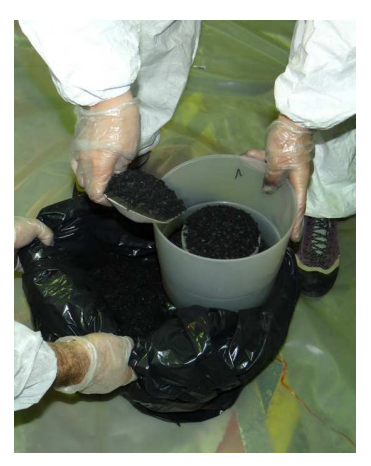

(a)

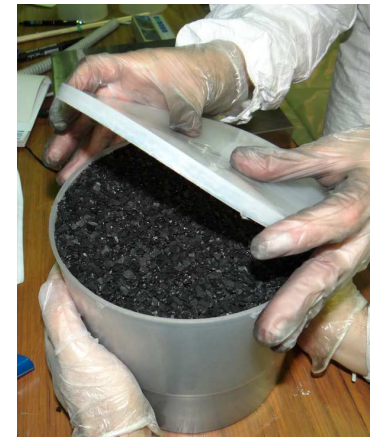

(b)

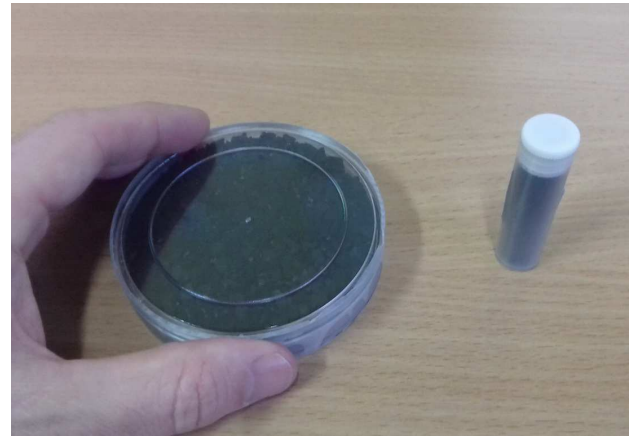

(c)

Figure 3. (a) Filling of the Marinelli beaker with an active charcoal. (b) Sealing of the Marinelli beaker. (c) Petri box and a plastic tube filled with active charcoal.

\subsection{Marinelli beakers}

Two types of Marinelli beakers were used with volume of $4 \mathrm{l}$ and $0.6 \mathrm{l}$. Before putting a required amount of the charcoal into the Marinelli beaker, it was necessary to place it in a plastic bag and to homogenize it by mixing (Figure 3 (a)). Usually, the sorbent was taken in layers each 5 or $10 \mathrm{~cm}$ deep and after homogenization stored in a Marinelli beaker. Every Marinelli beaker was hermetically sealed with a silicon glue and additionally with an adhesive tape (Figure 3 (b)). Together 15 samples with the volume of $4 \mathrm{l}$ and 13 samples with $0.6 \mathrm{l}$ were taken (see Table 1). The typical mass range of samples was about $1.5-1.7 \mathrm{~kg}$ for $4 \mathrm{l}$ Marinelli and $0.3-0.5 \mathrm{~kg}$ for $0.6 \mathrm{l}$ Marinelli. These samples have been measured using a high efficiency coaxial-type HPGe detector located at National Radiation Protection Institute (NRPI) in Prague (Czech Republic), suitable for high energy gamma lines detection coming from ${ }^{40} \mathrm{~K}$ and ${ }^{137} \mathrm{Cs}$.

\subsection{Petri boxes and plastic tubes}

Cylindrical Petri boxes $(\mathrm{D}=8 \mathrm{~cm}, \mathrm{H}=1.5 \mathrm{~cm})$ with a volume of $75 \mathrm{~cm}^{3}$ were also used. These containers were adapted to a Broad Energy Germanium (BEGe) planar detector installed at the LSM [12]. The typical mass of samples was about $25-35 \mathrm{~g}$ (see Table 1). Each box was hermetically sealed with an adhesive tape. Plastic tubes $(\mathrm{D}=1.3 \mathrm{~cm}, \mathrm{H}$ $=4.5 \mathrm{~cm}$ ) with a volume of $5.8 \mathrm{~cm}^{3}$ were also chosen. These containers were adapted to a well-type Germanium detector installed at Centre d'Etudes Nucléaires de BordeauxGradignan (CENBG) laboratory in the Plateforme Régionale de Spectrométrie Nucléaire en Aquitaine (PRISNA platform) [13]. The typical mass of samples was about 1.8 - $2.2 \mathrm{~g}$. Each tube was closed with a hermetic plug. These two containers coupled to planar and well-type detectors were suitable for measuring low gamma energies, such as the $46 \mathrm{keV}$ gamma line from ${ }^{210} \mathrm{~Pb}$.

For these two containers (see Figure 3 (c)), it was possible to collect the charcoal by hand at the top of each layer from $2 \mathrm{~cm}$ to about $50 \mathrm{~cm}$ before the charcoal was sucked out by the vacuum cleaner. In this case, the depth corresponds to the top of the 
Figure 4. Experimental setup used for the measurement of radon adsorption capacity $K$. The trap is filled with active charcoal and is cooled at the chosen temperature, usually $-30{ }^{\circ} \mathrm{C}$ or $-50{ }^{\circ} \mathrm{C}$.

layer and not to the mean layer depth. After the layer depth of $50 \mathrm{~cm}$, it was no more possible to take the samples by hand. Thus, we collected the charcoal samples after the homogenization in a plastic bag for each layer of $5 \mathrm{~cm}$ thickness, as it was described for the Marinelli beakers in the previous subsection. Finally, 27 samples were collected in Petri boxes and 25 samples in plastic tubes (see Table 1).

\subsection{Containers for $K$-factor measurements}

For $K$-factor measurements, 9 samples have been collected along the column at 0,23 , $38,61,78,103,123,163$ and $203 \mathrm{~cm}$ depth. The charcoal was collected in $250 \mathrm{~cm}^{3}$ air tight glass bottles in order to prevent humidity from air. As it will be described in the following section, only few grams of charcoal have been used for $K$-factor measurements.

\section{Study of the radon adsorption capacity as a function of time}

The radon adsorption capacity or dynamical adsorption coefficient $K$ was measured at the Center for Particle Physics in Marseille (CPPM) as a function of the column depth. The experimental setup used is shown in Figure 4. The carrier gas (nitrogen) is radonized in a radon source by the emanation of a metal plate coated with a thin ${ }^{226} \mathrm{Ra}$ layer maintained at a fixed temperature. The gas, radonized at a well-defined radon concentration, $C_{a}=900 \pm 24 \mathrm{~Bq} / \mathrm{m}^{3}$, is introduced in a copper cartridge filled with $2 \mathrm{~g}$ of the active charcoal located in a freezer at $-30{ }^{\circ} \mathrm{C}$ ( or $-50{ }^{\circ} \mathrm{C}$ ). All measurements have been carried out with a flow of $10 \mathrm{l} / \mathrm{h}$, at the pressure of $1 \mathrm{bar}$.

In order to establish when the adsorption/desorption equilibrium is reached in the adsorbent, the gas from the trap is continuously monitored with a commercial RAD7 radon detector [10]. When the breakthrough curve in the RAD7 reaches a constant value, the trap is isolated and disassembled from the setup. Then, the radon activity of 


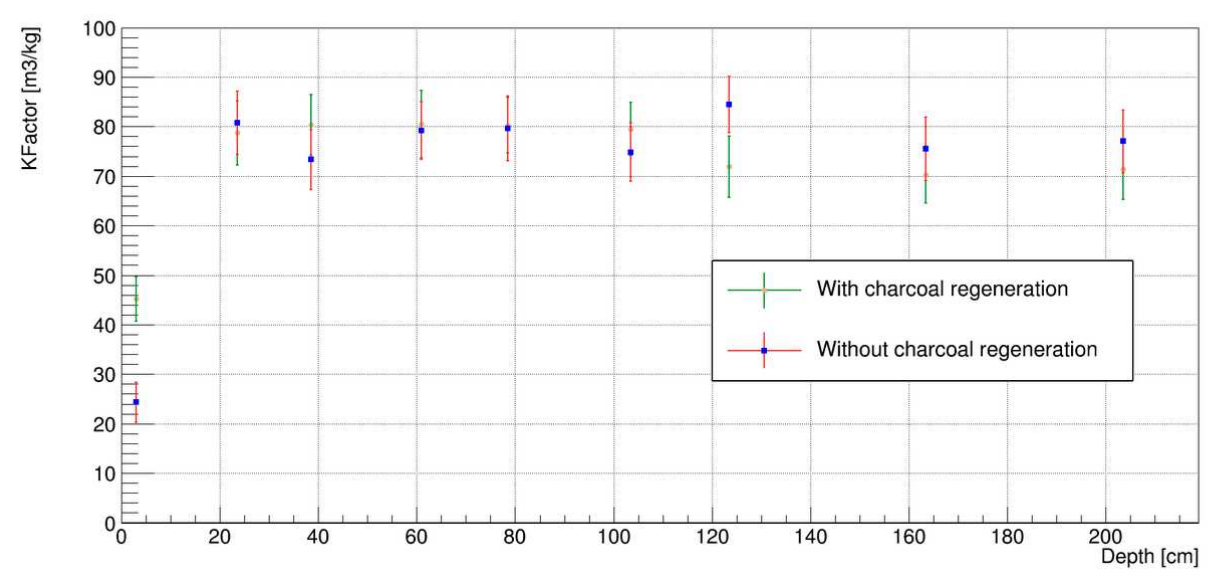

Figure 5. $K$-factor measured at $-30{ }^{\circ} \mathrm{C}$ as a function of the depth for charcoal without and with regeneration. The first point at "zero" mean layer depth has been put at $3 \mathrm{~cm}$ for a sake of better visibility.

the charcoal $C_{a}$ is measured by gamma spectrometry with a HPGe detector using the main gamma lines of ${ }^{214} \mathrm{~Pb}$ and ${ }^{214} \mathrm{Bi}$. The dynamic adsorption coefficient $K$ is then deduced from the ratio of radon activity in the gas $C_{g}$ and in the adsorbent $C_{a}$ from the Equation 1.

Two sets of measurements were performed. In the first one, the radon adsorption of the charcoal, as the function of the depth, was measured directly from the LSM charcoal column. In the second measurements, before the adsorption tests, the charcoal samples where heated up to $200{ }^{\circ} \mathrm{C}$ in vacuum (50 mbar) during $12 \mathrm{~h}$, in order to remove water traces or any volatile vapor or gas accumulated in the sample.

Figure 5 shows the $K$-factor values measured at $-30{ }^{\circ} \mathrm{C}$ as a function of the depth for the two configurations. As one can see, except for first layer of charcoal, which corresponds to the first $2 \mathrm{~cm}$, all the $K$-factors measured directly, without regeneration, are in good agreement independently of the depth in the charcoal column. The adsorption capacity of the first layer of charcoal is however around 3 times lower than in the rest of the column. The results after regeneration of the charcoal, show an equivalent $K$-factor for layers 2 to 9 . These results are also very close to those obtained in the previous test without regeneration. It is interesting to mention that these results are consistent with those obtained with new samples of the K48 charcoal from the same company and measured with the same setup $\left(\mathrm{K}=77 \pm 7 \mathrm{~m}^{3} / \mathrm{kg}\right)$ [11]. For layer number 1 the capacity of adsorption increases by a factor of two after regeneration but remains too low compared to other layers. The lower adsorption capacity of the first layer could be understood as an aging effect probably due to the presence of some volatile organic compounds (VOC) from the laboratory and the tunnel air. But the adsorption tests from the LSM charcoal column prove that most of the adsorption capacity of the RTF (about 95\%) remains constant after 9 years of running, i.e. 12 million of $\mathrm{m}^{3}$ filtered.

Additional measurements have been performed in order to measure the $K$-factor 
Table 2. $K$-factor values measured at $-50{ }^{\circ} \mathrm{C}$ for $\mathrm{K} 48$ activated charcoal using $\mathrm{N}_{2}$ and dried air.

\begin{tabular}{ccc}
\hline Sample & Carrier gas & $K$-factor $\left[\mathrm{m}^{3} / \mathrm{kg}\right]$ \\
\hline Layer 6 & $\mathrm{N}_{2}$ & $247 \pm 34$ \\
Layer 10 & $\mathrm{N}_{2}$ & $222 \pm 30$ \\
'Fresh' K48 charcoal & $\mathrm{N}_{2}$ & $232 \pm 13$ \\
\hline
\end{tabular}

around the operating temperature of the RTF, i.e. $-50{ }^{\circ} \mathrm{C}$ (unfortunately, it has not been possible to measure it at $-55{ }^{\circ} \mathrm{C}$ ). Measurements for layer 6 and 10 have been performed, still using pure nitrogen. The results for the $K$-factor are presented in Table 2. One can observe that $K$-factor is greater at $-50{ }^{\circ} \mathrm{C}$ compared to $-30{ }^{\circ} \mathrm{C}$ as expected from the Arrhenius law. The $K$-factor values are also consistent for layer 6 and 10 using $\mathrm{N}_{2}$ within error bars. Another study has been performed in Ref. [11] with fresh K48 charcoal at several temperatures $\left(20^{\circ} \mathrm{C}, 0{ }^{\circ} \mathrm{C},-30{ }^{\circ} \mathrm{C}\right.$ and $\left.-50{ }^{\circ} \mathrm{C}\right)$ and the value of $K$-factor at $-50{ }^{\circ} \mathrm{C}$ is also given in the Table 2 . This value is fully consistent with the charcoal samples located at layer 6 and layer 10. This is an additional proof that there is no ageing effect in the RTF after layer 1 . The RTF was equipped with three temperature sensors able to measure the gradient of temperature along the column. With a cooled air at $-55^{\circ} \mathrm{C}$ at the entrance, the temperature of the charcoal at the entrance (top) and exit (bottom) has been measured at $-54{ }^{\circ} \mathrm{C}$ and $-52{ }^{\circ} \mathrm{C}$, i.e. with a temperature gradient of $2{ }^{\circ} \mathrm{C}$ only. From the measurements at different temperature, it has been possible to extrapolate a $K$-factor at $53 \pm 1{ }^{\circ} \mathrm{C}$ of $280 \pm 18 \mathrm{~m}^{3} / \mathrm{kg}$. Considering a total mass of charcoal of $425 \pm 5 \mathrm{~kg}$ and a gas flow of $120 \pm 10 \mathrm{~m}^{3} / \mathrm{h}$, a suppression factor $e^{(K M) /(\Phi \tau)}$ of $1830_{-1220}^{+4970}$ of the RTF has been derived. Error bars are coming from the impact of the exponential function on the relative uncertainty, mainly the one from the air flow $\Phi$ and the $K$-factor.

\section{Results of gamma spectrometry measurements}

Analysis of all charcoal samples was done by the use of different types of HPGe detectors. The activity of radionuclides in the low energy region $\left(46.5 \mathrm{keV}\right.$ for $\left.{ }^{210} \mathrm{~Pb}\right)$ were measured from Petri boxes and plastic tubes samples using the Broad Energy Germanium (BEGe) and well-type HPGe detectors, located at LSM and CENBG laboratories, respectively. For activities of radionuclides with higher gamma energies, we used the Marinelli beakers measured with a coaxial HPGe detector with higher relative efficiency, located at NRPI institute. All these detectors were calibrated using several standard etalons: a radionuclide dissolved in a silicone gel with the density of $0.98 \mathrm{~g} / \mathrm{cm}^{3}$ placed in a plastic Marinelli beaker from the Czech Metrology Institute and several IAEA sediments (IAEA-314, IAEA-385 and IAEA-447) measured in different geometries for Petri boxes and plastic tubes. The activities were determined by taking into account the effective 


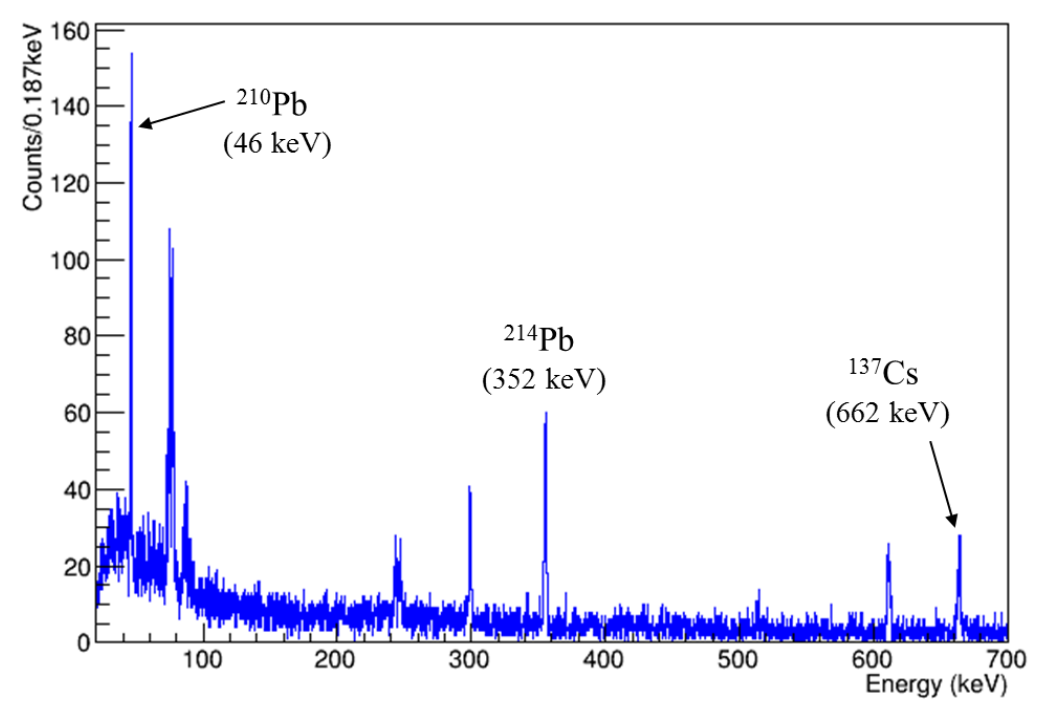

Figure 6. Gamma energy spectrum from 0 to $700 \mathrm{keV}$ for a charcoal sample obtained with a planar HPGe detector located at LSM.

density of each charcoal sample. A systematic uncertainty of about $7 \%$ has been estimated for all the HPGe detectors derived from the photopeak efficiency uncertainty.

Several radionuclides have been detected in the charcoal. An example is illustrated on Figure 6. It is possible to observe gamma lines coming from ${ }^{210} \mathrm{~Pb}(46 \mathrm{keV}),{ }^{137} \mathrm{Cs}$ (662 keV), ${ }^{226} \mathrm{Ra}$ and their daughters ${ }^{214} \mathrm{~Pb}$ and ${ }^{214} \mathrm{Bi}(295,351$ and $609 \mathrm{keV})$. The gamma line from ${ }^{40} \mathrm{~K}(1460 \mathrm{keV})$ is not shown in this plot.

In the following subsections each of detected isotopes will be discussed.

\subsection{Activity of ${ }^{210} \mathrm{~Pb}$}

The activity of ${ }^{210} \mathrm{~Pb}$ has been measured using the low energy gamma ray $46 \mathrm{keV}$ occurring after the $\beta$ decay. The results of the mass activities given in $\mathrm{Bq} / \mathrm{kg}$ are shown in the Table 3 with $1 \sigma$ statistical uncertainties. The activities have been corrected to correspond to the same date, i.e $1^{\text {st }}$ of January 2014. The two sets of data correspond to the two types of small containers used. The Petri box measurements exhibit positive ${ }^{210} \mathrm{~Pb}$ activities up to the last layer located at MLD of $254.5 \mathrm{~cm}$. This is due to the fact that they were performed with an ultra-low background BEGe planar detector located in the LSM and exhibiting a very low intrinsic contamination in ${ }^{210} \mathrm{~Pb}[12]$.

From these measurements, we observe a clear decrease of the activity as a function of the depth. One noticeable exception concerns the plastic tubes sampling measurements for which the activity of the first layer at $2 \mathrm{~cm}$ is below the value at $12 \mathrm{~cm}$. This can be explained by the fact that the input air was flushed inside the column through the plug (see Figure $2(\mathrm{~b})$ ) on its lateral sides. Thus, in the first layer at the top of the column, the charcoal was more exposed to radon at the edge compared to the center where the 
Table 3. Overview of measured activities of ${ }^{210} \mathrm{~Pb}$ from different sampling with respect to the mean layer depth (MLD). Activities have been normalized to the date $1^{\text {st }}$ of January 2014

\begin{tabular}{|c|c|c|c|c|}
\hline & \multicolumn{2}{|c|}{ Petri box / Planar Detector } & \multicolumn{2}{|c|}{ Plastic tubes / Well-type-detector } \\
\hline $\operatorname{MLD}[\mathrm{cm}]$ & $\mathrm{A}[\mathrm{Bq} / \mathrm{kg}]$ & $\sigma[\mathrm{Bq} / \mathrm{kg}]$ & $\mathrm{A}[\mathrm{Bq} / \mathrm{kg}]$ & $\sigma[\mathrm{Bq} / \mathrm{kg}]$ \\
\hline 2.0 & - & - & 485 & 10 \\
\hline 12.0 & 550 & 29 & 567 & 8 \\
\hline 22.0 & 371 & 20 & 395 & 7 \\
\hline 32.0 & 302 & 18 & 303 & 6 \\
\hline 42.0 & 247 & 14 & 239 & 5 \\
\hline 54.5 & - & - & 171 & 8 \\
\hline 59.5 & - & - & 122 & 8 \\
\hline 64.5 & 99.3 & 6.2 & 100.5 & 6.7 \\
\hline 74.5 & - & - & 63.1 & 2.5 \\
\hline 84.5 & 46.2 & 2.3 & 42.0 & 3.8 \\
\hline 94.5 & - & - & 28.7 & 2.0 \\
\hline 104.5 & 25.9 & 1.7 & 24.6 & 2.6 \\
\hline 114.5 & - & - & 22.1 & 2.1 \\
\hline 124.5 & 11.6 & 0.6 & 9.6 & 1.3 \\
\hline 134.5 & - & - & 8.5 & 1.2 \\
\hline 144.5 & - & - & 8.4 & 1.2 \\
\hline 154.5 & 7.55 & 0.51 & 6.4 & 2.1 \\
\hline 164.5 & - & - & 3.6 & 0.3 \\
\hline 174.5 & - & - & 3.8 & 0.8 \\
\hline 184.5 & 3.68 & 0.34 & - & - \\
\hline 194.5 & - & - & 2.1 & 0.6 \\
\hline 214.5 & 1.55 & 0.33 & - & - \\
\hline 224.5 & 2.28 & 0.34 & - & - \\
\hline 234.5 & 1.30 & 0.24 & - & - \\
\hline 254.5 & 0.91 & 0.18 & - & - \\
\hline
\end{tabular}

sample has been taken. After $10 \mathrm{~cm}$, this is more homogeneous due to the diffusion of radon along the radius. This lower value may also be explained by the fact that the $K$-factor is much lower in the first few $\mathrm{cm}$ layer (see section 5 ). So, the radon may have been less trapped in the first $2 \mathrm{~cm}$ layer and then less ${ }^{210} \mathrm{~Pb}$ is observed. Anyway, the fit of the activity curve with time has been applied to values starting from a mean layer depth of $12 \mathrm{~cm}$.

The activity as a function of the depth was fitted by an exponential function plus a constant background as follows:

$$
A(x)=A_{0} e^{-\frac{x}{X}}+A_{\text {res }}
$$

where $A$ is the mass activity in $\mathrm{Bq} / \mathrm{kg}$ at the depth $x$ and $A_{0}, X$ and $A_{\text {res }}$ are coefficients 
Table 4. Summary of the parameters derived from the fit of the two separated datasets and the combined datasets.

\begin{tabular}{ccccc}
\hline Parameter & Unit & Petri box sampling & Tubes sampling & Combined \\
\hline Activity at depth $0 A_{0}$ & $\mathrm{~Bq} / \mathrm{kg}$ & $824 \pm 40$ & $948 \pm 43$ & $908 \pm 27$ \\
Mean free path $X$ & $\mathrm{~cm}$ & $30.1 \pm 0.6$ & $28.1 \pm 0.7$ & $28.8 \pm 0.4$ \\
Intrinsic activity $A_{\text {res }}$ & $\mathrm{Bq} / \mathrm{kg}$ & $1.07 \pm 0.14$ & $1.07 \pm 0.39$ & $1.15 \pm 0.13$ \\
\hline
\end{tabular}

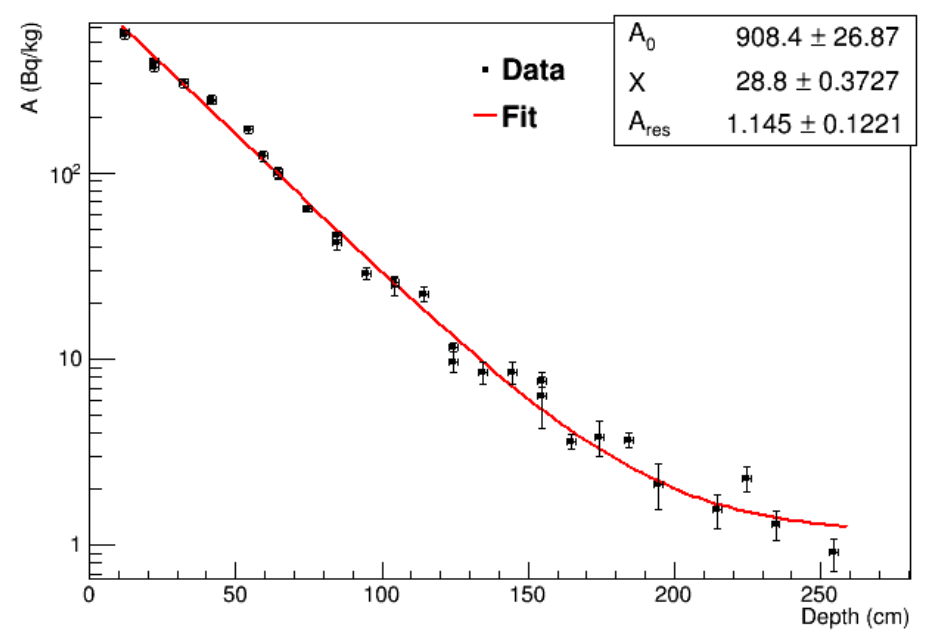

Figure 7. Measured activities of ${ }^{210} \mathrm{~Pb}$ as a function of the depth using combined data from Petri boxes and tubes sampling.

which will be explained below. The Figure 7 showed the measured values of the activity as a function of the depth, with an exponential fit for the combined data of Petri boxes and tubes.

The Table 4 summarizes the coefficients $A_{0}, X$ and $A_{\text {res }}$ derived from the two data sets and their combination from the global fit in Figure 7.

The coefficient $A_{0}$ represents the initial ${ }^{210} \mathrm{~Pb}$ activity at the top of the charcoal column, i.e. the maximal activity. Indeed, the ${ }^{210} \mathrm{~Pb}$ is the daughter nucleus of ${ }^{222} \mathrm{Rn}$ and is representative of the location where the radon atoms were trapped and had decayed. Thus, it was expected to obtain an exponential profile of the activity driven by the mean free path $X$ of radon atoms before being trapped. The mean free path $X$ has been already discussed in section 2 and Equation 3 and is directly related to the average retention time $\tau_{R}$ of the radon in the charcoal pores at a given temperature (here $-55{ }^{\circ} \mathrm{C}$ ). Finally, the coefficient $A_{\text {res }}$ is related to the intrinsic ${ }^{210} \mathrm{~Pb}$ activity at the bottom of the charcoal column. From Table 3, we conclude that the coefficients are consistent from the two sets of measurements within the uncertainties.

The initial ${ }^{210} \mathrm{~Pb}$ activity about $800-900 \mathrm{~Bq} / \mathrm{kg}$ observed at the top of the charcoal column seems consistent with a simple estimation. Indeed, the charcoal column was 


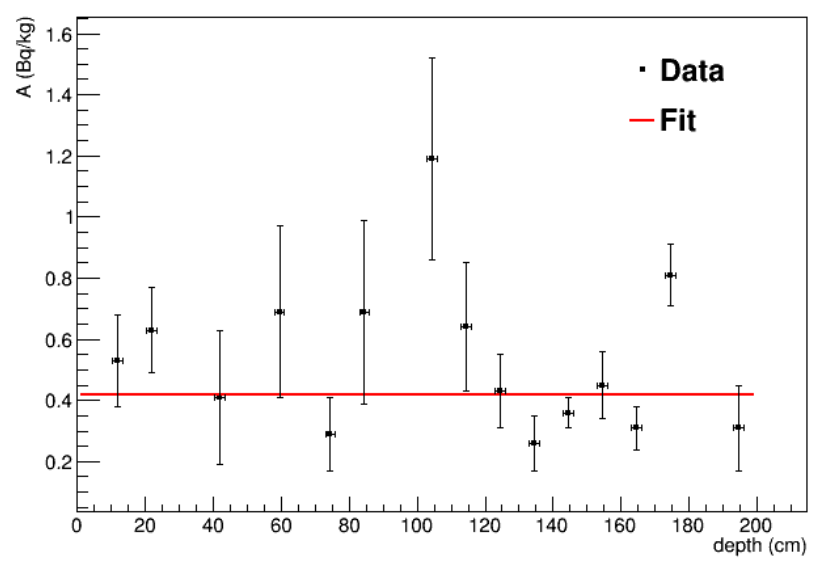

Figure 8. Measured activities of ${ }^{226} \mathrm{Ra}$ as a function of the mean depth layer using plastic tubes samples.

running during about 9 years without taking into account some shutdowns. Assuming a constant air flow of $120 \mathrm{~m}^{3} / \mathrm{h}$, an input activity of $20 \mathrm{~Bq} / \mathrm{m}^{3}$ and the decay of the ${ }^{210} \mathrm{~Pb}$ during the operation, one can derive a mass activity of $1000 \mathrm{~Bq} / \mathrm{kg}$ in the first $20 \mathrm{~cm}$ layer which is fully consistent with the measured activity taking into account uncertainties and the fact that the ${ }^{210} \mathrm{~Pb}$ activity has also decreased in 9 years.

The mean free path of radon atoms $X$ is equal to $28.8 \pm 0.4 \mathrm{~cm}$. Considering the total height of the column of $255 \pm 5 \mathrm{~cm}$, the reduction factor of the RTF is $6790_{-1720}^{+2370}$ from gamma spectrometry measurements. The comparison of the $\mathrm{Rn}$ reduction factor obtained through different methods will be discussed in section 7 . Obviously the height of the column has been well designed in order to decrease the radon level in the input air by at least 3 orders of magnitude.

Finally, the intrinsic ${ }^{210} \mathrm{~Pb}$ activity observed at the level of $1.1 \mathrm{~Bq} / \mathrm{kg}$ is probably coming from a natural intrinsic activity of the charcoal itself produced from coconut shells, as it will be discussed in more details in the next subsection for ${ }^{226} \mathrm{Ra}$.

\subsection{Activity of ${ }^{226} \mathrm{Ra}$ and its daughters}

The Figure 8 shows the results of the mass activity of ${ }^{226} \mathrm{Ra}$ measured with the K48 charcoal samples conditioned in plastic tubes. The ${ }^{226} \mathrm{Ra}$ activity has been deduced using the gamma rays from the ${ }^{214} \mathrm{~Pb}$ and ${ }^{214} \mathrm{Bi}$ radionuclides (see Figure 6) assuming a secular equilibrium with ${ }^{226} \mathrm{Ra}$ itself. The activities are ranged between 0.3 and $1.2 \mathrm{~Bq} / \mathrm{kg}$, with a mean value of $0.42 \pm 0.03 \mathrm{~Bq} / \mathrm{kg}$. This mean value is fully consistent with an activity of $0.46 \mathrm{~Bq} / \mathrm{kg}$ measured end of 2003 before the beginning of the charcoal column running [14].

The ${ }^{226} \mathrm{Ra}$ activity is obviously coming from the natural intrinsic activity of the coconut shells. It is a long-live radionuclide in the ${ }^{238} \mathrm{U}$ chain and is the direct progenitor of ${ }^{222} \mathrm{Rn}$ and ${ }^{210} \mathrm{~Pb}$. Assuming a secular equilibrium of ${ }^{210} \mathrm{~Pb}$ with ${ }^{226} \mathrm{Ra}$, we may expect 
$\mathrm{a}^{210} \mathrm{~Pb}$ intrinsic activity of about $0.42 \mathrm{~Bq} / \mathrm{kg}$ in the charcoal. This value is below the measured intrinsic activity of $1.1 \mathrm{~Bq} / \mathrm{kg}$ obtained from the fit shown in Figure 7 . This excess of ${ }^{210} \mathrm{~Pb}$ of about $0.7 \mathrm{~Bq} / \mathrm{kg}$ may be explained by the exposition of the coconut shells to radon deposition in the air during its lifetime. Anyway, this is not an issue in our study because it contributes as a constant background almost negligible along the height of the charcoal that do not affect the measurement of the $\mathrm{Rn}$ mean free path presented in the previous subsection.

Nevertheless, the intrinsic ${ }^{226} \mathrm{Ra}$ activity of the charcoal may be an issue for residual self-radon emanation. Indeed, a self radon emanation may occur from the charcoal itself due to the ${ }^{226} \mathrm{Ra}$ content. The self-emanation of activated charcoal have been recently pointed out but it has been measured at higher temperature from 20 to $140{ }^{\circ} \mathrm{C}$ [7]. Here the RTF is running at $-55^{\circ} \mathrm{C}$ so we believe that the radon emanation from $\mathrm{K} 48$ charcoal is highly suppressed. In addition, due to the high trapping efficiency of the RTF, the self radon emanation may only come from the last layers of the column which reduce dramatically its effect. A rough estimation gives a hypothetical contribution below $1 \mathrm{mBq} / \mathrm{m}^{3}$ in radon for an activity of $0.42 \mathrm{~Bq} / \mathrm{kg}$ of ${ }^{226} \mathrm{Ra}$ in $\mathrm{K} 48$ activated charcoal. Thus it seems not to be an issue for our purpose but might be a problem for very challenging low Rn activity well below $1 \mathrm{mBq} / \mathrm{m}^{3}$.

For the following radionuclides measured with higher gamma energies, we will present only the data from Marinelli beakers, i.e. with a higher mass of the charcoal and a more homogeneous samples.

\subsection{Activity of ${ }^{40} \mathrm{~K}$ and ${ }^{137} \mathrm{Cs}$}

The results of mass activities of ${ }^{40} \mathrm{~K}$ in active charcoal using Marinelli beakers are presented in Figure 9 (a) as a function of the depth. One can observe that the activity is almost constant, ranging from 239 to $292 \mathrm{~Bq} / \mathrm{kg}$, and independent of the depth with a mean value of $276 \pm 7 \mathrm{~Bq} / \mathrm{kg}$. This is not surprising as the ${ }^{40} \mathrm{~K}$ is usually found in coconut, from which the charcoal was produced. Therefore, as a primordial radionuclide with a very long half-life, it is consistent to measure a uniform activity of ${ }^{40} \mathrm{~K}$ in all layers of active charcoal.

The evolution of ${ }^{137} \mathrm{Cs}$ mass activity as a function of the depth is shown in Figure 9 (b). The samples were the same as for ${ }^{40} \mathrm{~K}$ and the activities are ranged from 1.26 to $1.62 \mathrm{~Bq} / \mathrm{kg}$. One can observe that the activity is almost constant and independent of the depth with a mean value of $1.35 \pm 0.04 \mathrm{~Bq} / \mathrm{kg}$, except the first point.

The ${ }^{137} \mathrm{Cs}$ radionuclide is coming from human activities (nuclear fallouts from atomic bombs or nuclear power plant accidents). The nuclear fallouts on the soil and surfaces induced a deposition of ${ }^{137} \mathrm{Cs}$ in the environment and may be found in food or drinks. This is why ${ }^{137} \mathrm{Cs}$ has already been found in some coconuts and active charcoal $[15,16]$. Thus, the ${ }^{137} \mathrm{Cs}$ activity measured in our samples is an intrinsic contamination of the coconut itself. Nevertheless, the first sample located at the entrance of the charcoal column (MLD of $7 \mathrm{~cm}$ ) has a much higher activity than the other samples. Despite 


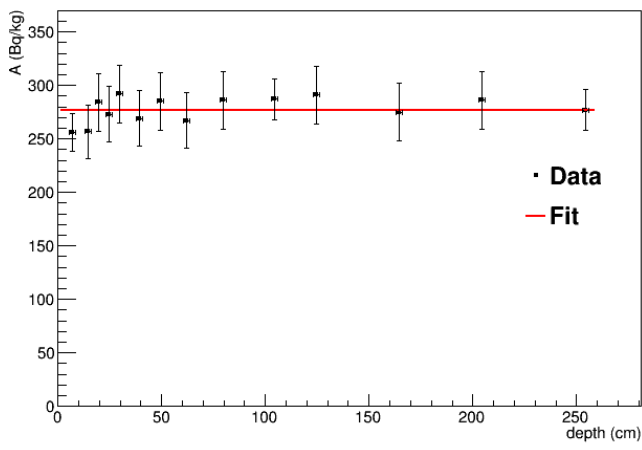

(a)

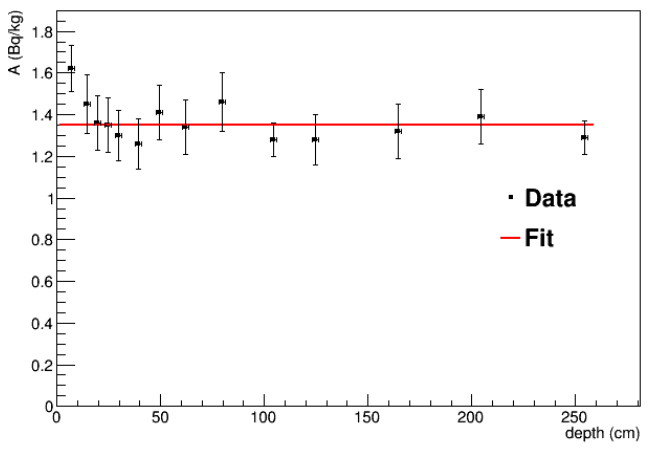

(b)

Figure 9. Measured activities of ${ }^{40} \mathrm{~K}$ (a) and ${ }^{137} \mathrm{Cs}$ (b) as a function of the mean layer depth using Marinelli beakers samples.

the fact that it may be a statistical fluctuation at $2-3 \sigma$, this may be also explained by an additional ${ }^{137} \mathrm{Cs}$ deposition from the input air during the 9 years of operation at LSM. Indeed, the first layer of active charcoal is more exposed to this phenomenon than deeper layers. The presence of ${ }^{137} \mathrm{Cs}$ in the air is well-known. The most recent incident is the Fukushima nuclear power plant accident in 2011. At this occasion, some traces of ${ }^{137}$ Cs have been found at LSM in the particle filters used for the renewing of air in the laboratory [17]. Despite the presence of filters before entering in the charcoal column, it is possible to accumulate some ${ }^{137} \mathrm{Cs}$ in the first layers of active charcoal due to the non-attached fraction of ${ }^{137} \mathrm{Cs}$ passing through the filters. One can note that, if ${ }^{137} \mathrm{Cs}$ would originated from the air, the ${ }^{7} \mathrm{Be}$ which is also present in the air (total activity of $830 \mathrm{~Bq} / \mathrm{kg}$ ) would be detected in the upper layers of the sorbent as well. However, measurements show that the total activity of ${ }^{7} \mathrm{Be}$ in the sorbent was 1000 times lower.

\section{Discussion}

In the section, we will discuss the main results of the Rn trapping efficiency in the RTF obtained from three complementary methods: $K$-factor measurements, gamma spectrometry measurements of ${ }^{210} \mathrm{~Pb}$ and online $\mathrm{Rn}$ measurements performed before and after the RTF during 9 years.

The results of the measurements of the $K$-factor for K48 activated charcoal have demonstrated a stability of its adsorption capacity during the 9 years of the RTF operation at LSM (see section 5). This is a proof that such device can be used during many years without any significative aging, except the very first part (few $\mathrm{cm}$ ) of the activated charcoal probably exposed to some volatile organic compounds (VOC) from the laboratory and the tunnel air. This means that most of adsorption capacity of the RTF remains constant after a decade. One can envisage to replace regularly, like every year, the first layer of the RTF by fresh charcoal in order to keep exactly the same performances. The dynamic adsorption coefficient $K$ has been estimated to be 
Table 5. Summary of the adsorption parameters and RTF radon suppression factor using three independent techniques. These results are taking into account a total mass of $425 \pm 5 \mathrm{~kg}$, an air flow of $120 \pm 10 \mathrm{~m}^{3} / \mathrm{h}$, a height of $255 \pm 5 \mathrm{~cm}$ for the charcoal column and a radon mean lifetime of 5.5 days.

\begin{tabular}{ccccc}
\hline Technique & $\mathrm{K}\left(\mathrm{m}^{3} / \mathrm{kg}\right)$ & $\mathrm{X}(\mathrm{m})$ & $\tau_{R}(\mathrm{~d})$ & Suppression Factor \\
\hline$K$-factor meas. with N2 at $-53 \pm 1{ }^{\circ} \mathrm{C}$ & $280 \pm 18$ & $0.339 \pm 0.061$ & $41.3 \pm 6.6$ & $1830_{-1220}^{+4970}$ \\
${ }^{210} \mathrm{~Pb} \gamma$ spectrometry meas. & - & $0.289 \pm 0.004$ & $47.6 \pm 1.2$ & $6790_{-1720}^{+2370}$ \\
radon online meas. & - & - & - & $2000 \pm 950$ \\
\hline
\end{tabular}

$280 \pm 18 \mathrm{~m}^{3} / \mathrm{kg}$ at $-53 \pm 1^{\circ} \mathrm{C}$ with pure nitrogen. With this method, it has been possible to derive both the mean free path $X$ of the radon atoms and the average retention time $\tau_{R}$ which are microscopic parameters of the behavior of the radon in K48 activated charcoal. It has been also possible to derive the radon suppression factor of $1830_{-1220}^{+4970}$ between the entrance and the exit of the RTF. The results for this are summarized in the first line of the Table 5.

It has been demonstrated in section 6 that the ${ }^{210} \mathrm{~Pb}$ activity as a function of the depth of charcoal measured by gamma spectrometry was following an exponential curve as expected from the radon trapping profile. From the gamma spectrometry measurements, the half-depth and thus the radon mean free path $X$ has been deduced as well as the suppression factor of $6790_{-1720}^{+2370}$ (see the second line of the Table 5).

The third method is the online radon measurement performed at the exit of the RTF during the 9 years with electrostatic radon detectors. A suppression factor of 2000 \pm 950 has been measured during the running of the RTF considering the measured radon activity of the air at the input $\left(20 \pm 5 \mathrm{~Bq} / \mathrm{m}^{3}\right)$ and at the output $\left(10 \pm 4 \mathrm{mBq} / \mathrm{m}^{3}\right)$ of the RTF [9].

Considering the large uncertainties derived from the three methods, we can conclude that the suppression factor is roughly consistent ranging from 1800 to 6800 . Thus, the RTF installed at LSM has proven its capacity to purify the radon in air by more than 3 orders of magnitude down to $10 \mathrm{mBq} / \mathrm{m}^{3}$ during 9 years, even using only one of the two charcoal columns. In order to reach even better air purification down to $1 \mathrm{mBq} / \mathrm{m}^{3}$, one has to increase the height of the column or to choose a new sorbent with a higher adsorption capacity $K$-factor. In that case, the radon self emanation of the sorbent due to its ${ }^{226} \mathrm{Ra}$ content may be an issue that has to be taken into account, especially for the last layer of the column. In our work, the K48 activated charcoal has an activity of $0.42 \mathrm{~Bq} / \mathrm{kg}$ in ${ }^{226} \mathrm{Ra}$ but we did not know the radon emanation rate at the running temperature of $-50{ }^{\circ} \mathrm{C}$. As far as we know, such radon emanation measurement of sorbent at low temperature have not yet been performed. An ideal scenario for an efficient and cheap RTF would be to use mainly a sorbent with a high dynamic adsorption coefficient, even with radium impurities, and to use at the end of the chromatographic column few $\mathrm{cm}$ of a very radiopure sorbent in order to adsorb the possible radon emanated from the former sorbent. 


\section{Additional analyses of the charcoal}

Within complete analysis of the charcoal used in RTF a multi-element, organic compounds and SEM analyses have been also performed. The multi-element analysis of the charcoal samples was carried out by instrumental neutron activation analyses (INAA) at the Nuclear Physics Institute of the Czech Academy of Sciences (NPI). Detailed description and discussion of the INAA analytical procedures performed at NPI are given in Ref. [18, 19]. Results of this analysis show uniform distribution of determined elements with no dependence on the depth of the column. For the organic compounds analysis, a gas chromatographymass spectrometry (GCMS) carried out at the Institute of Rock Structure and Mechanics of the Czech Academy of Sciences (IRSM) was used. In this study, a statistically significant content increase of organic compounds in upper layers was determined. Further, the SEM (Scanning Electron Microscope) analysis of charcoal samples did not show any anomalies.

\section{Conclusions}

In order to provide a radon-free air to the various ultra-low background experiments hosted at LSM, a RTF using K48 activated charcoal has been designed and built in 2004 . The device at LSM was well adapted to fulfill the requirements in radon suppression by at least three orders of magnitude with a radon activity in air down to $10 \mathrm{mBq} / \mathrm{m}^{3}$. After 9 years of operation the RTF has been stopped and dismantled for maintenance operation. This was a unique opportunity to analyse such a device after a decade of operation. An original study has thus been conducted in order to understand how the radon was trapped in the column as a function of the depth. To do so, the column has been sampled in several layers of active charcoal in order to measure both the dynamic adsorption coefficient $K$ and its radioactivity, especially the ${ }^{210} \mathrm{~Pb}$ isotope which provides a picture of the radon trapping localization in the RTF.

From the $K$-factor measurements, it has been shown that despite a decade of running, the $\mathrm{K} 48$ activated charcoal has still the same adsorption capacity at $-50{ }^{\circ} \mathrm{C}$ than before along the $2.5 \mathrm{~m}$ height of the column, except the first few $\mathrm{cm}$ where a decrease by a factor 3 has been observed. This aging effect is probably due to an exposure to some volatile organic compounds present in the air. This demonstrates the high reliability of the device where $95 \%$ of the charcoal has still the same adsorption capacity even after having filtered about 12 million $\mathrm{m}^{3}$ of dried air.

Several radioactive isotopes have been also measured by gamma spectrometry, i.e. ${ }^{210} \mathrm{~Pb},{ }^{226} \mathrm{Ra},{ }^{40} \mathrm{~K}$ and ${ }^{137} \mathrm{Cs}$. It has been demonstrated that the activity of ${ }^{210} \mathrm{~Pb}$ as a function of the depth has an exponential behavior, as expected from the radon trapping profile. We have deduced a value of the mean free path $X$ for radon atoms of 0.289 $\pm 0.004 \mathrm{~m}$ as well as a radon suppression factor of the RTF between the entrance and the exit of about 6 800. Taking into account the large uncertainties, this latter value is in agreement with the suppression factor deduced from the $K$-factor measurements but 
also from online radon measurements. We have also measured the activity of $0.42 \mathrm{~Bq} / \mathrm{kg}$ in ${ }^{226} \mathrm{Ra}$ which is the progenitor of the ${ }^{222} \mathrm{Rn}$ in the uranium chain and which exhibits a constant activity along the column. The possibility of a radon contribution at the exit of the RTF due to the self emanation of the charcoal is not completely ruled out but it is unlikely due to the low running temperature of the RTF that prevents the radon to exit easily for most of the column except maybe the last few $\mathrm{cm}$. Anyway, this may be a crucial issue for smaller trapping facility or for experiments that need to purify the air below $1 \mathrm{mBq} / \mathrm{m}^{3}$, that may be solved by adding a layer of a more radiopure activated charcoal at the bottom of the RTF.

\section{Acknowledgments}

We acknowledge the LSM staff for their technical assistance during the charcoal sampling. We would like also to thank M. Nakahata and the SK collaboration for transferring the know-how of the RTF to the LSM. This work was supported by the Ministry of Education, Youth and Sports of the Czech Republic under the Contract Number LM2015072.

\section{References}

[1] Arnold R et al. 2005 (NEMO-3 Collaboration) Nucl. Inst. Meth. A 53679

[2] Augier $\mathrm{C}$ for the NEMO Collaboration, Technical Performance of the NEMO-3 detector "Advantages and Limitations", LAL Orsay, HDR thesis, 2005

[3] Arnold R et al. 2009 (NEMO-3 Collaboration) Nucl. Inst. Meth. A 606449

[4] Arnold R et al. 2015 (NEMO-3 Collaboration) Phys. Rev. D 92072011

[5] Takeuchi Y et al. 1999 Phys. Lett. B 452418

[6] Mitsuda C et al. 2003 Nucl. Instr. Meth. A 497414

[7] Pushkin K et al. 2018 arXiv:1805.11306v3 [physics.ins-det]

[8] Activated charcoal K48 specification document, https://www . euroquarz.com/fileadmin/user_ upload/Fotos/produkte/aquarbo/AQUARBO_K835_K48_englisch.pdf, Last time accessed: 2019-04-30

[9] Nachab A 2007 AIP Conference Proceedings 89735

[10] RAD7 radon detector specification document, https://durridge.com/documentation/RAD7\% 20Specifications.pdf, Last time accessed: 2019-04-30

[11] Noel R et al. 2015 AIP Conference Proceedings 1672070001

[12] Loaiza P et al. 2011 Nucl. Instr. Meth. A $\mathbf{6 3 4} 64$

[13] Perrot F et al. 2012 J. Environ. Radioact. 11461

[14] Hubert Ph 2003, NEMO-3 Collaboration internal note, ph-2004-03

[15] Robinson W L et al. 2009 J. Environ. Radioact. 10076

[16] Rubio Montero M P et al. 2009 Appl. Radiat. Isotopes 67953

[17] Loaiza P et al. 2012 J. Environ. Radioact. 11466

[18] Řanda Z et al. 2007 Geostand. Geoanal. Res. 31275

[19] Mizera J and Řanda Z 2010 J. Radioanal. Nucl. Chem. 284157 